\title{
Implementasi DevOps pada Pengembangan Aplikasi e-Skrining Covid-19
}

\author{
Tohirin ${ }^{1}$, Sri Farida Utam ${ }^{2}$, Septian Rheno Widianto ${ }^{3}$, Widhy Al Mauludyansah ${ }^{4}$ \\ Program Studi Pascasarjana Magister Sistem Informasi \\ STMIK LIKMI Bandung \\ Jl. Ir. H. Juanda 96 Bandung 40132 \\ tohirin07@gmail.com¹, utamigeulis@gmail.com², septian.rheno@yahoo.de ${ }^{3}$ widhy.am@gmail.com ${ }^{4}$
}

Diterima : 30 April 2020. Disetujui: 19 Mei 2020. Dipublikasikan: 26 Mei 2020

\begin{abstract}
Problems in the build, test and deploy phases are common in the system development life cycle with Agile Scrum, which takes a lot of time and causes unscheduled releases. DevOps is expected to provide a solution to the problem. This research provides build, test and deploy automation solutions for those working in the Agile Scrum SDLC environment, especially projects that use the PHP programming language and the Laravel framework. This research is the practice of applying DevOps to SDLC Agile Scrum from the e-Screening Covid-19 application which is a web-based software, developed with the PHP programming language, the Laravel framework, and has previously adopted SDLC Agile Scrum. The method used in this research is to use the DevOps life cycle. From this research it was concluded that DevOps can be implemented in the development of the Covid-19 e-Screening application well where code integration occurs easily, smooth daily builds and health checks and code eligibility occur every time there is a commit and push from the developer. DevOps has facilitated the process of developing software on a web interface using GitLab.
\end{abstract}

Keywords: automation; test, build, deploy; application; cicd; e-screening; covid-19.

Abstrak - Masalah pada fase build, test dan deploy umum terjadi pada siklus hidup pengembangan sistem dengan Agile Scrum, di mana memakan banyak waktu dan menyebabkan rilis tidak sesuai jadwal. DevOps diharapkan dapat memberi solusi masalah tersebut. Penelitian ini memberikan solusi otomatisasi build, test dan deploy bagi mereka yang bekerja di lingkungan SDLC Agile Scrum, khusunya proyek yang menggunakan bahasa pemrograman PHP dan kerangka kerja Laravel. Penelitian ini merupakan praktik penerapan DevOps pada SDLC Agile Scrum aplikasi e-Skrining Covid-19 yang merupakan perangkat lunak berbasis web, dikembangkan dengan bahasa pemrograman PHP, kerangka kerja Laravel, dan sebelumnya telah mengadopsi SDLC Agile Scrum. Metode yang dipakai dalam penelitian ini adalah memakai siklus hidup DevOps. Dari penelitian ini dihasilkan bahwa DevOps dapat diimplementasikan pada pengembangan aplikasi eSkrining Covid-19 dengan baik di mana penggabungan kode terjadi dengan mudah, build harian lancar dan pemeriksaan kesehatan dan kelayakan kode terjadi setiap kali ada komit dan push dari pengembang. DevOps telah memudahkan proses pengembangan perangkat lunak pada satu antar muka web menggunakan GitLab.

Kata kunci: otomatisasi; tes, build, deploy; aplikasi; cicd; e-skrining; covid-19.

\section{PENDAHULUAN}

E-Skrining merupakan aplikasi skrining untuk mandiri maupun lembaga kesehatan seperti Puskesmas, klinik dan rumah sakit. E-Skrining Covid-19 dikembangkan atas banyaknya permintaan dari Puskesmas yang menginginkan agar di lembaganya terdapat aplikasi untuk skrining pasien. Pengembangan aplikasi e-Skrining Covid-19 juga merupakan salah satu bentuk partisipasi aktif dalam memerangi pandemik yang sedang melanda dunia, khususnya Indonesia.

E-Skrining Covid-19 merupakan perangkat lunak berbasis web yang dikembangkan dengan bahasa pemrograman PHP dengan kerangka kerja Laravel. Dalam pengembangan dan pemeliharaan, eSkrining menggunakan siklus hidup pengembangan sistem Agile dengan kerangka kerja Scrum.
Siklus hidup pengembangan sistem (SDLC) merupakan metodologi untuk merancang, membangun, mengembangkan dan memelihara informasi dan proses sistem [1] . Dengan menerapkan aturan SDLC yang ada dapat memberikan pemahaman bagaimana sebuah Sistem Informasi (SI) dapat mendukung kebutuhan bisnis, merancang dan membangun sistem sesuai kebutuhan pengguna [2] . Proyek SDLC merupakan proyek direktif, yakni teratur dan terencana. Standar proyek SDLC mengharuskan fase rilis dan pada setiap fase akan ada proses build dan deploy. Tahap deploy menunjukkan bahwa pengembangan kode telah usai. Kemudian kode akan dibangun dan digunakan di lingkungan Testing. Jika terdapat bug yang muncul di lingkungan Testing, kode harus diperbaiki untuk selanjutnya dibangun kembali dan digunakan di lingkungan Pra-produksi atau Produksi. 
Tahun ini, kerangka kerja Agile telah berusia lebih dari satu dekade, namun sampai sekarang masih banyak orang membicarakannya. Topik yang menjadi pusat perhatian dari Agile antara lain kemampuannya yang dapat menekan biaya, meningkatkan kecepatan dan kualitas, serta memberi motivasi untuk memberdayakan karyawan guna mendukung perkembangan dan keberhasilan sebuah perusahaan. Scrum adalah yang paling populer dalam kerangka kerja Agile [3]. Pada kerangka kerja Scrum terdapat Sprint dan tim yang akan bekerja di dalamnya. Setelah Sprint selesai, Demo selesai dan Definition of Done (DoD) terpenuhi sesuai dengan user story, lantas setiap tim akan mengintegrasikan kode mereka dan melakukan build untuk digunakan di lingkungan stage atau test. Alat manajemen konfigurasi akan digunakan untuk mengintegrasikan kode. Di sini masalah yang sebenarnya muncul. Memperbaiki masalah ini akan memakan banyak waktu dan menyebabkan waktu rilis tidak sesuai jadwal. Masalah pada fase build dan deploy sangat umum dan sering terjadi pada lingkungan kerja Agile. Hal ini juga yang terjadi dalam pengembangan aplikasi e-Skrining Covid-19. DevOps diharapkan dapat menjadi solusi hal tersebut. Gambar 1 menunjukkan bagaimana proses koding dan testing pada Agile dan perbandingannya dengan menggunakan DevOps.

Agile
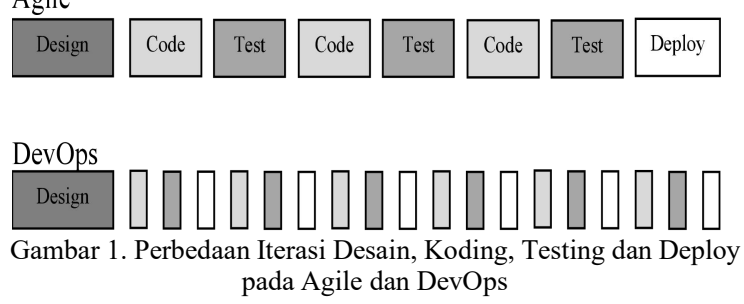

DevOps (development and operations) adalah studi konseptual pengembangan dan pengiriman perangkat lunak terhadap infrastruktur dengan mengambil pendekatan kolaboratif dan integratif antara pengembang (Dev) dan operasional perangkat lunak (Ops) [4] . DevOps merupakan pendekatan organisasi dengan tujuan menciptakan kolaborasi, interaksi dan empati lintas fungsi dan divisi [5] . Adopsi DevOps adalah salah satu contoh langkah mempererat kerjasama antara tim IT di mana hal itu sangat dibutuhkan dalam pengembangan dan pemeliharaan perangkat lunak [6].

Metode DevOps terbukti dapat mengurangi beberapa tahapan pengembangan yang ada pada metode lama [7]. DevOps mampu mempersingkat waktu antara pengembangan dan pengoperasian perangkat lunak tanpa mengurangi kualitas perangkat lunak itu sendiri [8]. DevOps mengurangi kesenjangan antara tim pengembang, tim operasi dan pengguna aplikasi yang memungkinkan untuk mendeteksi masalah sejak dini. Adopsi DevOps dapat mengimplementasikan pengembangan yang berkesinambungan dan rilis aplikasi yang lebih sering kepada pengguna [9] . Tidak hanya itu DevOps juga mengubah proses dan praktik rekayasa perangkat lunak menjadi lebih cepat yang juga meningkatkan keandalan, stabilitas, ketahanan dan keamanan lingkungan produksi [10]. Sebagai bonus, adopsi DevOps ternyata dapat mengurangi tingkat stres pada karyawan karena Agile mengharuskan fase rilis yang sering [11]. Untuk mendukung kesuksesan semua kegiatan tersebut dibutuhkan kemampuan untuk mengoperasikan berbagai alat bantu dan teknik yang berbeda [12].

Perangkat lunak dengan rilis lebih awal dan frekuensi tinggi menjadikan organisasi memiliki kesempatan tinggi untuk memenangkan persaingan di kancah industri [13]. DevOps mampu menjadikan perangkat lunak rilis lebih awal dengan frekuensi yang tinggi. Metode DevOps diharapkan menjadi solusi mempercepat rilis pengembangan aplikasi eSkrining Covid-19.

\section{METODOLOGI PENELITIAN}

Metodologi penelitian ini menggunakan DevOps life cycle sebagaimana dapat dilihat pada Gambar 2.

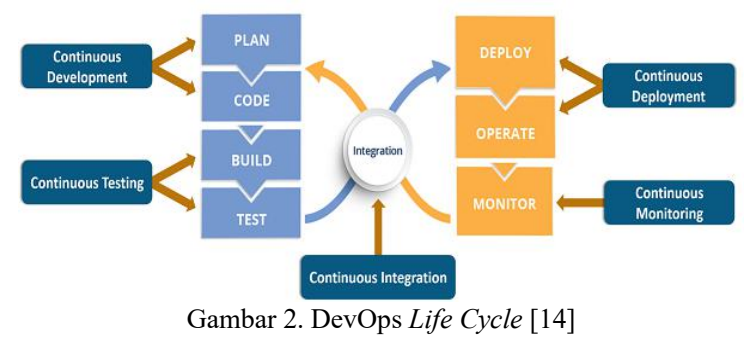

\section{A. Continuous Development}

Pada fase ini terlibat di dalamnya proses perencanaan dan koding perangkat lunak. Visi proyek disepakati dan ditetapkan pada fase perencanaan kemudian pengembang mulai melakukan koding aplikasi. Tidak ada alat secara khusus untuk melakukan perencanaan, tetapi ada sejumlah alat untuk memelihara kode (kontrol versi), misalnya svn, git, jira dan mercurial. Selain itu alat bantu seperti Maven, Selenium dan Gradle juga dapat dipakai dalam fase ini guna mengemas kode menjadi file yang dapat dieksekusi untuk diteruskan ke fase berikutnya.

\section{B. Continuous Testing}

Pada fase ini perangkat lunak yang dikembangkan akan diuji secara terus menerus setiap kali ada perubahan atau komit dari pengembang. Alat uji yang dapat digunakan seperti TestNG, Selenium, Junit dan sebagainya. Alat-alat ini memungkinkan QA untuk menguji beberapa bari 
kode secara menyeluruh guna memastikan bahwa tidak ada kekurangan dalam fungsionalitas. Dalam fase ini, wadah Docker dapat digunakan untuk melakukan simulasi lingkungan pengujian. Seluruh fase pengujian ini dapat diotomatisasi dengan bantuan alat Continuous Integration seperti Gitlab dan Jenkins.

Terdapat perbedaan yang mendasar antara testing dengan Agile tanpa kombinasi metode DevOps dan testing Agile dengan kombinasi DevOps sebagaimana dapat dilihat pada tabel berikut.

\section{TABEL I. PERBEDAAN TESTING PADA AGILE DAN} DEVOPS [15]

\begin{tabular}{ll}
\hline \multicolumn{1}{c}{ Testing pada Agile } & Testing dengan DevOps \\
\hline $\begin{array}{l}\text { Tes sedini dan sesering } \\
\text { mungkin }\end{array}$ & Tes terus menerus \\
\hline $\begin{array}{l}\text { Otomatisasi pengujian } \\
\text { sebanyak mungkin }\end{array}$ & $\begin{array}{l}\text { Hampir semua dilakukan } \\
\text { otomatisasi }\end{array}$ \\
\hline $\begin{array}{l}\text { Integrasi dan pengujian } \\
\text { berkelanjutan merupakan nilai } \\
\text { lebih }\end{array}$ & $\begin{array}{l}\text { Integrasi dan pengujian } \\
\text { berkelanjutan adalah wajib }\end{array}$ \\
\hline $\begin{array}{l}\text { Kode yang berpotensi dapat } \\
\text { dikirim pada akhir sprint }\end{array}$ & $\begin{array}{l}\text { Kode yang berpotensi } \\
\text { dapat dikirim mengikuti } \\
\text { setiap integrasi }\end{array}$ \\
\hline
\end{tabular}

\section{Continuous Integration}

Fase ini merupakan inti dari seluruh siklus hidup DevOps di mana integrasi pengembangan perangkat lunak dan proses operasional dilakukan. Setiap komit yang dilakukan pengembang sedini mungkin harus dideteksi, terlebih jika terdapat bug.Integrasi kode melibatkan kompilasi, ulasan kode, unit testing, functional testing, integration testing dan packaging. Alat populer yang bisa dipakai seperti Gitlab dan Jenkins.

\section{Continuous Deployment}

Pada fase ini kode disebarkan ke server produksi. Penting juga untuk memastikan bahwa kode tersebut digunakan dengan benar di semua server.

\section{E. Continuous Monitoring}

Fase ini sangat penting dari siklus hidup DevOps di mana kinerja aplikasi perlu terus dipantau. Pada fase ini informasi penting terkait penggunaan perangkat lunak perlu dicatat guna mengenali fungsionalitas aplikasi yang tepat. Kesalahan sistem seperti alokasi memori terlalu rendah, server tidak dapat dijangkau, bad gateway, dan sebagainya diselesaikan pada fase ini. Alat yang bisa dipakai pada fase ini seperti Zabbix, PRTG, Nagios, Cacti, Splunk, ELK Stack, Sensu dan NewRelic.

\section{HASIL DAN PEMBAHASAN}

Hasil penelitian yang dilakukan pada eSkrining Covid-19 sebagaimana menggunakan DevOps life cycle adalah sebagaimana berikut:

\section{A. Continuous Development}

Terlibat di dalam fase ini tahap perencanaan dan pengembangan perangkat lunak. Tahap perencanaan merupakan proses dasar untuk memahami mengapa perangkat lunak dibangun dan sekaligus menentukan bagaimana tim proyek akan membangunnya. Hasil dari tahapan ini digabungkan menjadi permintaan sistem (system request) yang disajikan kepada sponsor proyek dan panitia pada akhir fase ini sebagai bahan pengambilan keputusan apakah pengembangan sistem dapat dilanjutkan [2].

Gambar berikut adalah salah satu form skrining manual yang disampaikan stakeholder (dalam hal ini Puskesmas) kepada product owner eSkrining yang kemudian dimasukan sebagai user story pada product backlog Scrum. Form ini juga yang menjadi salah satu landasan kenapa perangkat lunak e-Skrining Covid-19 dibuat.

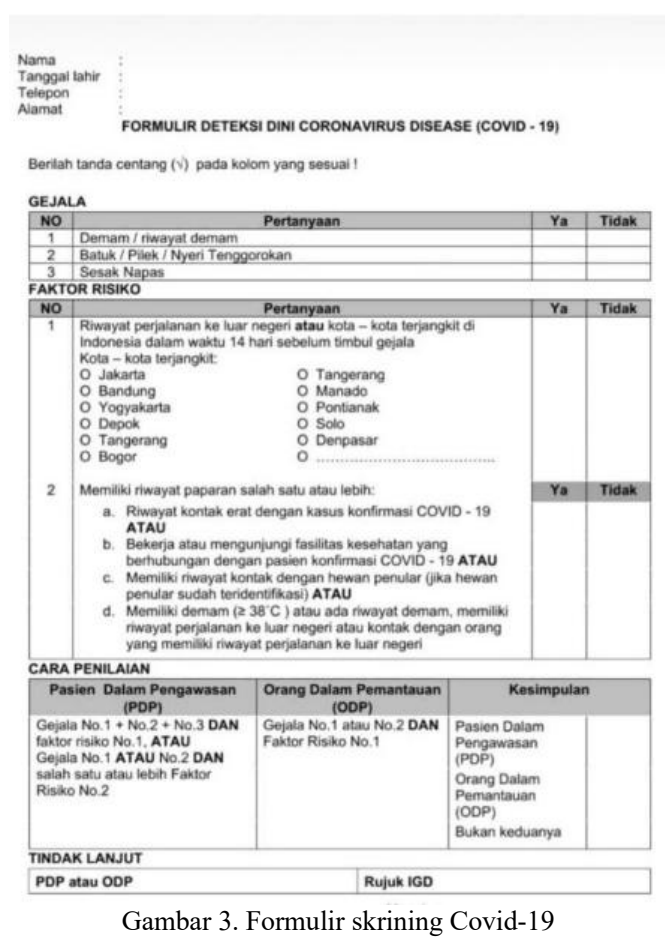

Pada fase perencanaan juga ditentukan teknologi yang akan digunakan untuk keseluruhan proses DevOps life cycle, arsitektur teknologi dan infrastruktur yang akan dipakai pada lingkungan produksi sebagaimana dapat dilihat pada TABEL II, III, dan IV. 
TABEL II. ARSITEKTUR TEKNOLOGI

\begin{tabular}{lll}
\hline No & Tipe & Software Usulan \\
\hline 1 & Sistem Operasi & Linux CentOS 7 \\
\hline 2 & Framework & Laravel 6 dan React Native \\
\hline 3 & DBMS & MariaDB 10.4 \\
\hline
\end{tabular}

TABEL III. INFRASTRUKTUR DI LINGKUNGAN PRODUKSI

\begin{tabular}{lll}
\hline No & Tipe & Software Usulan \\
\hline 1 & Server & Cloud pada data center pihak ketiga \\
\hline 2 & Memori & RAM $4 G B$, disk $40 G B$ \\
\hline 3 & DBMS & MariaDB 10.4 \\
\hline 4 & Web Server & Nginx, PHP74-FPM \\
\hline
\end{tabular}

TABEL IV. TEKNOLOGI DEVOPS YANG DIPAKAI

\begin{tabular}{lll}
\hline No & Tipe & Software Usulan \\
\hline 1 & Versioning & Git \\
\hline 2 & CI Server & GitLab \\
\hline 3 & Testing & Code execption \\
\hline 4 & Test dan staging server & Docker \\
\hline
\end{tabular}

Selanjutnya ditetapkan sprint untuk melakukan koding pengembangan perangkat lunak e-Skrining. Sebagaimana TABEL V di atas, versioning yang dipakai adalah Git dengan server CI yang dipakai adalah GitLab.
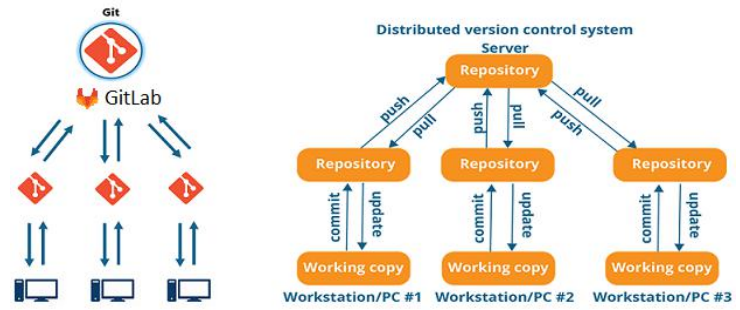

Gambar 4. Versioning Git dan Server CI GitLab

\section{B. Continuous Testing}

Pada tahap ini dilakukan integrasi build setiap kali ada komit dan push koding yang telah ditulis pengembang ke Server CI GitLab. Kemudian GitLab akan melakukan pengujian unit, functional dan api. Berikut adalah .gitlab-ci.yml untuk fase testing.

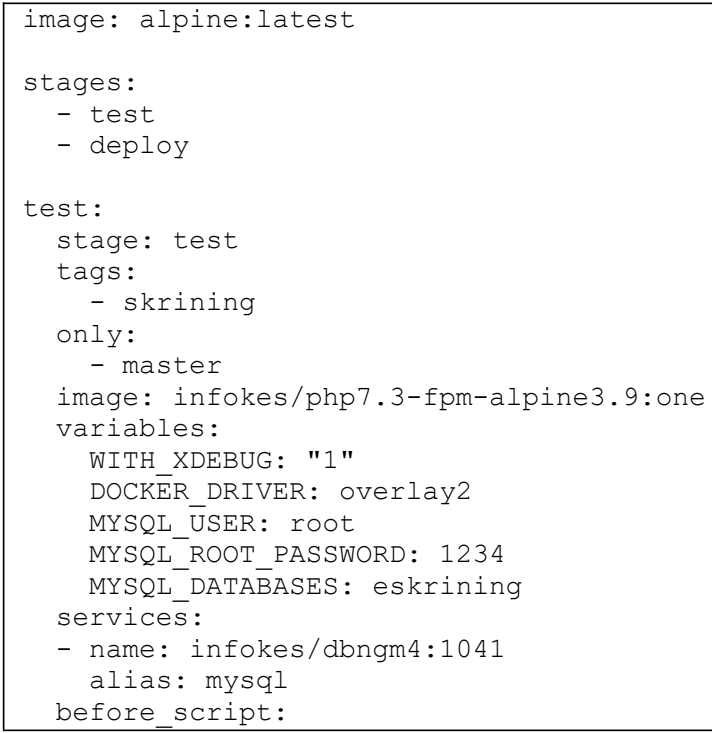

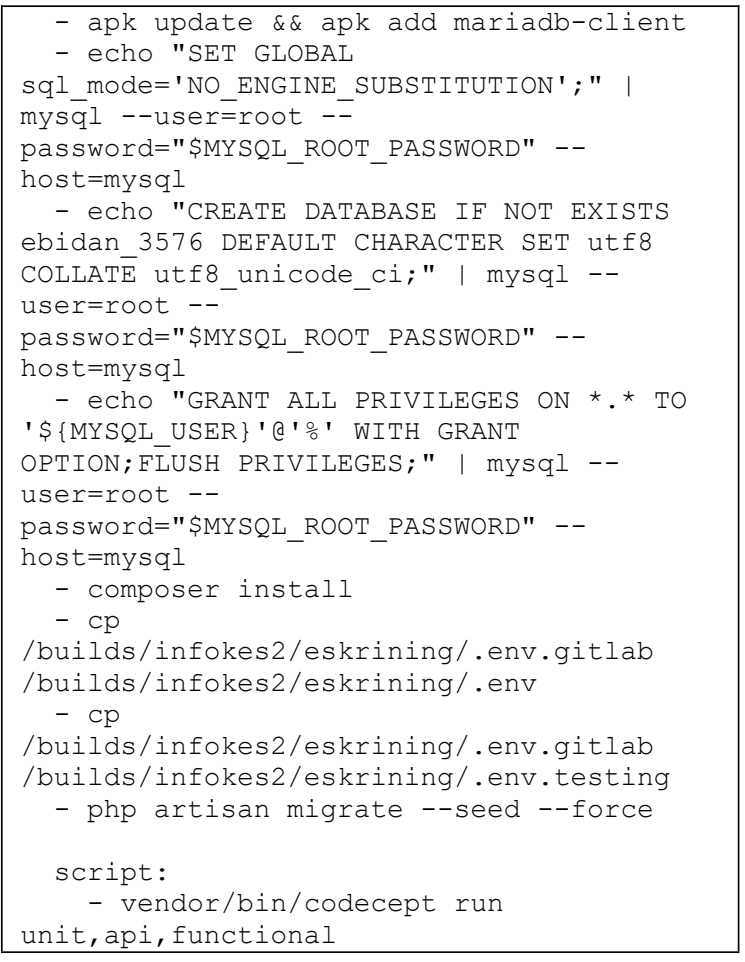

Output dari code $\mathrm{CI}$ di atas adalah sebagaimana gambar berikut.

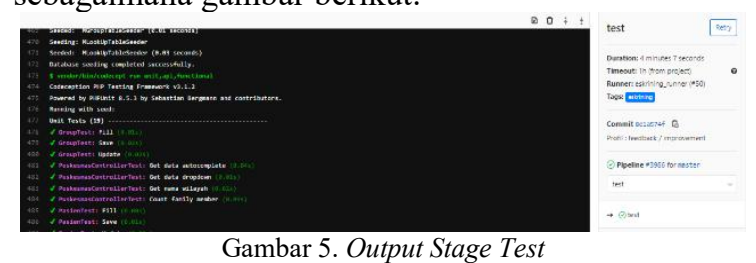

\section{Continuous Integration}

Pada tahap ini secara keseluruhan proses DevOps dikoordinisakan oleh Gitlab sebagaimana gambar berikut.

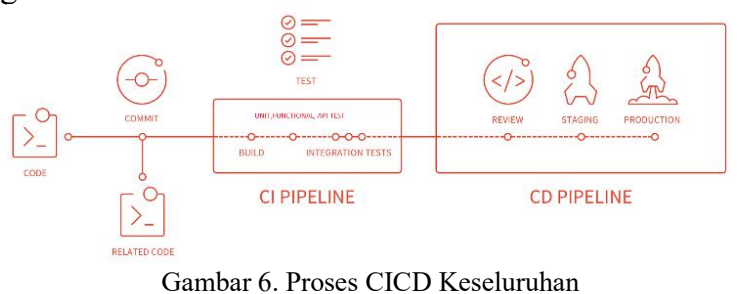

\section{Continuous Deployment}

Pada tahap ini terdiri dari: stagi create yaitu mendorong branch master ke branch 6.0 dengan tujuan agar antara mode pengembangan kode dibedakan dengan mode produksi; stage deploy, yaitu penyebaran ke lingkungan produksi untuk selanjutnya akan dipakai oleh pengguna (operate). Dengan .gitlab-ci.yml, berikut alur yang dikerjakan.

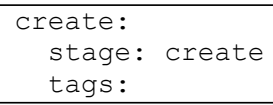




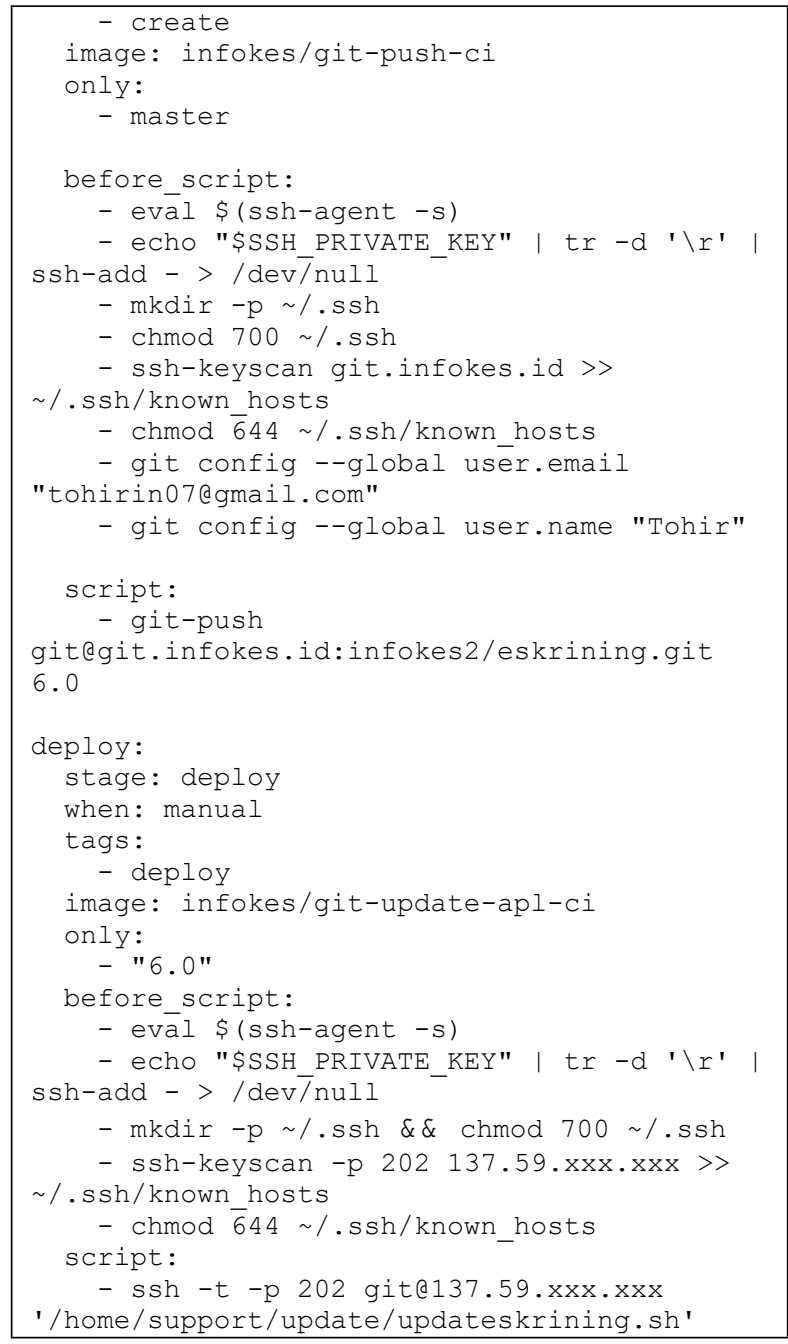

Output dari kode CI stage create di atas adalah sebagaimana gambar berikut.

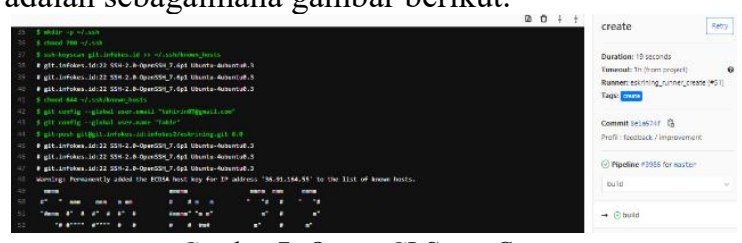

Gambar 7. Output CI Stage Create

Sedangkan output dari stage deploy di atas adalah sebagaimana gambar berikut.

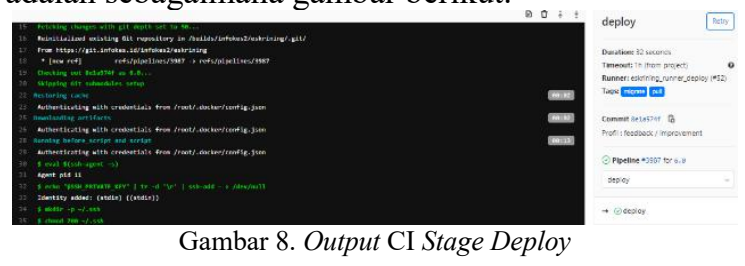

\section{E. Continuous Monitoring}

Pada tahap ini dipantau semua aktivitas server produksi, meliputi penggunaan CPU, RAM, hardisk, bandwidth dan lain sebagainya. Selain itu setiap ada error atau bugs yang dilaporkan oleh pengguna dicatat untuk dijadikan sebagai bahan evaluasi berikutnya. Alat pantau yang digunakan adalah Zabbix.

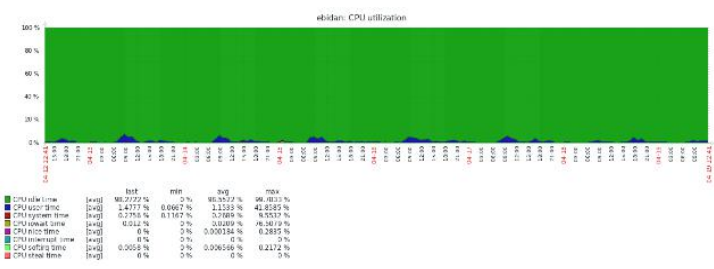

Gambar 9. Penggunaan Resource CPU

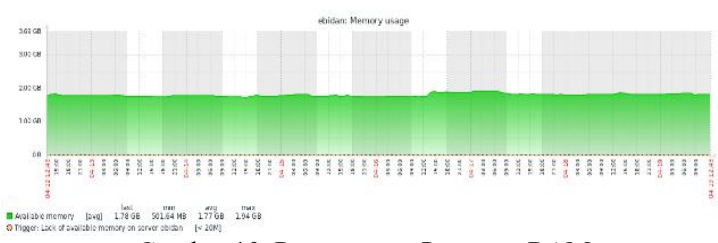

Gambar 10. Penggunaan Resource RAM

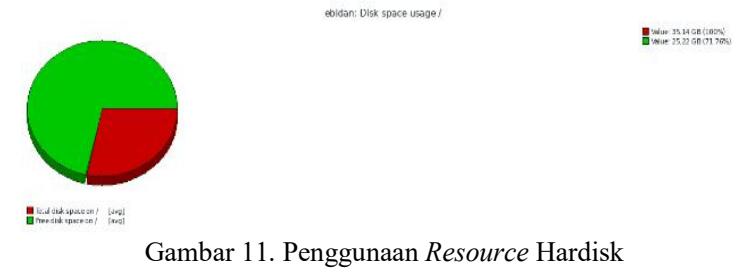

\section{F. Tampilan Aplikasi}

Tampilan halaman aplikasi e-Skrining Covid19 adalah sebagaimana gambar berikut.

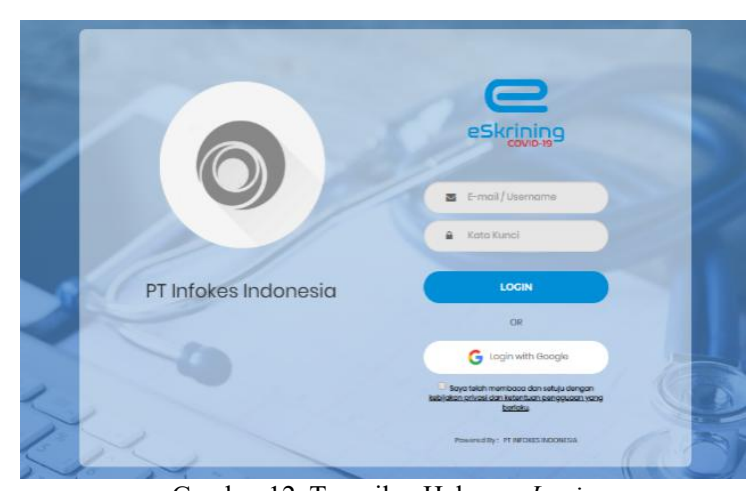

Gambar 12. Tampilan Halaman Login

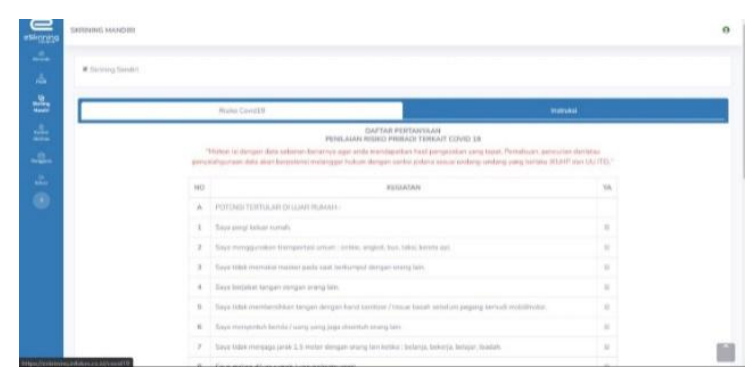

Gambar 13. Tampilan Halaman Skrining Mandiri 


\section{KESIMPULAN}

Dari pemaparan secara keseluruhan penelitian ini, adopsi DevOps dapat diimplementasikan pada pengembangan aplikasi e-Skrining Covid-19 dengan baik, di mana penggabungan kode terjadi dengan mudah, build harian lancar dan pemeriksaan kesehatan dan kelayakan kode terjadi setiap kali ada komit dan push dari pengembang. DevOps telah memudahkan dalam melakukan proses pengembangan perangkat lunak pada satu antar muka web dengan alat bantu GitLab.

\section{REFERENSI}

[1] Alhamidi, "Membangun Sistem Aplikasi Untuk Seleksi Calon Mahasiswa Undangan," J-Click, pp. 48-55, 2016.

[2] N. Syamsiyah dan M. F. Sesunan, "Penerapan Metode System Life Cycle Development Dan Project Management Body Of Knowledge Pada Pengembangan Sistem Informasi," Ikraith Informatika, 2018.

[3] N. Naik dan P. Jenkins, "Relax, It's a Game: Utilising Gamification in Learning Agile Scrum Software Development," Systems Engineering (ISSE) 2019 International Symposium, pp. 1-3, 2019.

[4] P. Jha dan R. Khan, "A Review Paper on DevOps: Beginning and More To Know," International Journal of Computer Applications (0975 - 8887), vol. 180, no. 48, pp. 16-20, 2018.

[5] A. Dyck, R. Penners dan H. Lichter, "Towards Definitions for Release Engineering and DevOps," Proceedings of the IEEE/ACM 3rd International Workshop on Release Engineering, 2015.

[6] CaTechnology, "TechInsights Report: What Smart Businesses Know About DevOps,” 2013.

[7] A. Taryana, A. Fadli dan S. R. Nurshiami, "Merancang Perangkat Lunak Sistem Penjaminan Mutu Internal (SPMI) Perguruan Tinggi yang Memiliki Daya Adaptasi Terhadap Perubahan Kebutuhan Pengguna secara Cepat dan Sering," Al-Azhar Indonesia Seri Sains dan Teknologi, 2020.

[8] F. Erich, C. Amrit dan M. Daneva, "A Qualitative Study of DevOps Usage in Practice," Journal of Software: Evolution and Process, pp. 1-25, 2017.

[9] F. Erich, C. Amrit dan M. Daneva, "DevOps Literature Review,"University of Twente, 2014.

[10] S. I. Mohamed, "DevOps shifting software engineering strategy Value based perspective," IOSR Journal of Computer Engineering, 2015.

[11] L. Riungu-Kalliosaari, S. Makinen, L. E. Lwakatare, J. Tiihonen dan T. Männistö, "DevOps Adoption Benefits and Challenges in Practice: A Case Study," 17th International Conference on Product Focused Software Process Improvement, pp. 590-597, 2016.

[12] A. Brunnert, A. v. Hoorn, F. Willnecker, A. Danciu, W. Hasselbring, C. Heger, N. Herbst, P. Jamshidi, R. Jung, J. v. Kistowski, A. Koziolek, J. Kroß, S. Spinner, C. Vögele dan W, "Performance-oriented DevOps: A Research Agenda," SPEC RG DevOps Performance Working Group, 2015.

[13] A. Fox, D. Patterson dan S. Joseph, Engineering Software as a Service: An Agile Approach Using Cloud Computing, Strawberry Canyon LLC, 2014.

[14] Arvind, "DevOps Life cycle: Everything You Need To Know About DevOps Life cycle Phases," 26 November
2019. [Online]. Available: https://www.edureka.co/blog/devops-lifecycle/. [Diakses 20 April 2020].

[15] Cognizant, "Jumpstarting DevOps with Continuous Testing," December 2015. [Online]. Available: https:/www.cognizant.com/whitepapers/JumpstartingDevOps-with-Continuous-Testing-codex1719.pdf. 